\title{
Prevalence of Geriatric Depression and Alexithymia and their association with sociodemographic characteristics in a sample of elderly persons living in Buenos Aires, Argentina
}

\author{
María Florencia Tartaglini' \\ Carol Dillon ${ }^{2}$ \\ Paula Daniela Hermida? \\ Carolina Feldberg ${ }^{3}$ \\ Verónica Somale ${ }^{4}$ \\ Dorina Stefani'
}

Abstract

Objective: to evaluate the prevalence of Geriatric Depression and Alexithymia and their association with sociodemographic characteristics in independent elderly persons without known depression. Method: a cross-sectional study was conducted, based on a nonprobabilistic, intentional type sampling strategy. A total of 176 independent men and women aged over 60 years residing in the city of Buenos Aires, Argentina, were evaluated through individual interviews using the following instruments: a sociodemographic (ad hoc) questionnaire, an adapted version of the questionnaire of the Yesavage Geriatric Depression Scale (V-15) and the Latin American Alexithymia LAC TAS-20 Scale. The Chi-squared and Student's t-tests were used and the Odds Ratio was calculated, with a probability of error less than or equal to 0.05 . Results: The mean age was 73 years $( \pm 7.1$ years) and $72.7 \%$ of the participants were women. The prevalence of Geriatric Depression was $35.8 \%$, while that of Alexithymia was $50.6 \%$. The presence of Geriatric Depression was significantly associated with the female gender and with individuals who did not work. High Alexithymia values were observed among those with primary education and a low occupational level. Conclusion: The evaluation of Geriatric Depression and Alexithymia in clinical care is recommended, and the social determinants of the health of the elderly should also be considered in the diagnosis and treatment of these conditions.

\footnotetext{
Consejo Nacional de Investigaciones Científicas y Técnicas, Instituto de Investigaciones Cardiológicas, Laboratorio de Psicología Social y Salud, (ININCA-UBA-CONICET). Ciudad Autónoma de Buenos Aires, Argentina.

2 Consejo Nacional de Investigaciones Científicas y Técnicas, Centro de Educación Médica e Investigaciones Clínicas, Sección de Investigación y Rehabilitación de Enfermedades Neurocognitivas (CONICETCEMIC-SIREN). Ciudad Autónoma de Buenos Aires, Argentina.

3 Consejo Nacional de Investigaciones Científicas y Técnicas, Fundación para la Lucha contra las Enfermedades Neurológicas de la Infancia, Servicio de Neurología Cognitiva, Neuropsicología y Neuropsiquiatría (CONICET- FLENI). Ciudad Autónoma de Buenos Aires, Argentina.

4 Instituto de Neurociencias Buenos Aires (INEBA), Unidad de Neurociencias Cognitivas. Ciudad Autónoma
} de Buenos Aires, Argentina.

Research funding: Fundación del Instituto de Neurociencias Buenos Aires (Foundation of the Buenos Aires Neurosciences Institute) No. 16 (INEBA, 2013/2017). Beliefs about the meaning of life and its relationship with well-being, funded by the Consejo de Investigaciones Científicas y Técnicas (Council of Scientific and Technical Research) (CONICET) 112/20110100295, (2012-2014), headed by Dr. Dorina Stefani.

Keywords: Depression. Alexithymia. Elderly. 


\section{INTRODUCTION}

The aging of the world population is an intrinsic process of demographic transition. In Argentina, $14 \%$ of the population is made up of 60 -year-old adults and the city of Buenos Aires is considered to have the oldest population in the country $(17 \%)^{1}$.

Analyzing the process of aging involves considering how the socio-cultural system influences the lifestyle of the senescent. Psychosocial factors affect the etiology of diseases by determining the attitudes and behaviors of individuals in relation to the health-disease process ${ }^{2}$. Although the developments within successful aging show that aging is not synonymous with disease, an increase in the number specific pathologies that affect health are also observed in this stage of the life cycle ${ }^{3}$.

In this context, the study of depression in the elderly has become one of the most significant problems for public health ${ }^{4}$. Specifically, Geriatric Depression is one of the most frequent and incapacitating health conditions among this population. It is estimated that around $10 \%$ of the elderly living in the community and between 15\% and $35 \%$ of those residing in geriatric institutions suffer from depressive disorders ${ }^{5}$. Balmón Cruz and Dorado Primo ${ }^{6}$ describe how, from 70 years of age onwards, these symptoms become more common due to the increase of physical health problems and disabilities, as well as affective and economic losses.

In recent decades the association between Major Depressive Disorders and Alexithymia has also begun to be studied ${ }^{7}$. Rojas Ramírez y García Méndez ${ }^{8}$ describe how Sifneos was the first to propose using the Greek term Alexithymia to describe the difficulties in identifying and communicating feelings, limited imaginary capacity, rigid and stereotyped interpersonal relations and predominance of operative thinking suffered by psychosomatic patients.

Different positions can be observed when analyzing the relationship between Depression and Alexithymia: López-Ibor Aliño ${ }^{9}$ argues that the characteristics of Alexithymia coincide with certain manifestations of Depression, whereas Taylor et al. ${ }^{10}$ affirmed that Alexithymia is an independent construct and distinct from Depression.
Fisch $^{11}$, meanwhile, suggests that Alexithymia is concomitant with Depression, causing it to be masked through somatic symptoms, and describes it as a multidimensional construct that responds to situational stressors. Despite the controversy that surrounds this link, studies that analyze the association of high levels of Alexithymia and Anxiety and Depression in elderly persons have begun to thrive ${ }^{12}$.

Regarding sociodemographic characteristics and their relation to the appearance of depressive symptoms, scientific literature emphasizes that the different types of losses that appear in old age, as well as the limitations of access to activities that promote well-being, could influence the increase of the prevalence of chronic diseases, which contribute to the emergence of depression. The interruption of work $^{13}$ leads to a number of deprivations (income, purchasing power, the social role of working, etc.) and produces a change in the social clock. It has also been observed that both psychic morbidity and coping behavior are different in males and females ${ }^{14,15}$. In this regard, some studies have highlighted factors associated with the appearance of depressive symptoms, such as the female gender, advanced age and living alone ${ }^{16}$. Arancibia and Behar ${ }^{7}$, in a bibliographic review on the subject, point out the probable association between age, gender, educational level and Alexithymia and Depression ${ }^{8,9}$.

Based on the above, the objective of this study was to evaluate the prevalence of Geriatric Depression and Alexithymia and their association with the sociodemographic characteristics of independent elderly persons without known depression.

\section{METHODS}

A cross-sectional study was performed ${ }^{17}$. The subjects of the sample were selected from the target population (elderly persons, middle socioeconomic level and residents of the city of Buenos Aires and its areas of influence, Argentina) through a non-probabilistic, intentional type sampling strategy, in the clinical care area of the Instituto de Neurociencias Buenos Aires (the Buenos Aires Neurosciences Institute) (INEBA), the Instituto de Investigaciones Cardiológicas Profesor Dr. Alberto C. Taquini (the Professor Dr. Alberto C. Taquini Cardiological Investigation Institute) and the Hospital Dr. César Milstein. 
The research protocol and informed consent form were approved by the respective Ethics and Research committees of the institutions described.

The inclusion criteria were male and female independent subjects who were older than 60 years. Likewise, those with a previously known diagnosis of major depression, according to the Diagnostic and Statistical Manual of Mental Disorders, Fifth Edition ${ }^{18}$ (DSM V), (Alzheimer's Disease, Frontotemporal Dementia, Parkinson's Disease, and other neurodegenerative diseases), or who were diagnosed with Schizophrenia, Substance and/or Alcohol Abuse or Dependence, according to the DSM V $\mathrm{V}^{18}$, were excluded. This information was provided by general practitioners from medical records. Following the pilot study the evaluation protocol selected was administered to the elderly through an individual interview conducted by the lead researcher of the project, and lasted approximately 40 minutes. The instruments used were: a) a sociodemographic data questionnaire: in order to obtain the socio-demographic and cultural profile of the elderly, a questionnaire was used, elaborated on an ad hoc basis, consisting of 22 questions, open and closed with fixed options, information about the variables of age, gender, nationality, marital status, education, level of employment and current employment status; b) an adapted version of the Yesavage Geriatric Depression Questionnaire ${ }^{5}$ : this is one of the most used instruments among the elderly population and is recommended by the Spanish Society of Family and Community Medicine. It is a self-administered scale that was designed by Yesavage et al. ${ }^{19}$ specifically for the elderly population. For the present study, the version adapted and validated into Spanish by Martínez de la Iglesia et al. ${ }^{5}$. This is composed of 15 items, and has an internal consistency was 0.99 , using the Kuder-Richarson test (a variation of Cronbach's Alpha for dichotomous variables). The sensitivity was $81.1 \%$ and the specificity was $76.7 \%$. The cutoff scores of the scale are: 0 to 4 normal, 5 to 8 mild depression, 8 to 11 moderate depression and 12 to 15 severe depression; C) the Latin American Consensual Toronto Alexithymia Scale LAC TAS-2020: through a Likert scale, this evaluates Alexithymia by means of three factors or subscales: I) difficulty identifying feelings and distinguishing between feelings and the bodily sensations of emotional arousal, (II) difficulty in describing feelings to others, and (iii) externally oriented thinking. The overall reliability was calculated by Varela et al. ${ }^{20}$ through Cronbach's Alpha, yielding values between 0.77 and 0.78 , considered adequate for this type of study. It is composed of 20 items with five possible response options. According to their answers, the subjects are placed in a continuum of between 20 and 100 points, with the cut-off scores: $<40$ non-Alexithymic, between 41 and 55 indefinite Alexithymia, >56 defined Alexithymia.

A population prevalence of $10 \%$ of depression, a confidence limit of $+5 \%$ of absolute precision and a 95\% confidence interval were used to calculate the sample size to estimate frequencies, and a sample of 139 subjects was calculated.

Regarding statistical analyzes, the sociodemographic variables and the prevalence of Geriatric Depression and Alexithymia were described in the total sample according to the distribution of the data. Likewise, the $\chi^{2}$ (Chi-squared) test of statistical independence was used to evaluate the probable association between the variables Geriatric Depression and Alexithymia. Finally, the $\chi^{2}$ test and Student's t-test were used to evaluate the association of sociodemographic variables with Geriatric Depression and Alexithymia, respectively.

To assess the strength of the statistically significant associations, Odds Ratio and 95\% confidence intervals were calculated. For these statistical analyzes, a probability of error value of less than or equal to 0.05 was used.

\section{RESULTS}

During the period from January 2013 to March 2015, 237 possible candidates were registered for participation in the study. Of these, 22 did not meet the inclusion criteria, 39 met one of the exclusion criterion (12 had moderate cognitive impairment, four had Parkinson's disease, 16 had already experienced depression and seven were excluded for other reasons). Therefore 176 subjects were analyzed. The mean age was 73 years ( \pm 7.1 years) and $72.7 \%$ of the participants were women. The rest of the demographic characteristics are shown in Table 1. 
The prevalence of Geriatric Depression in the sample was 35.8\% (95\%CI 29.1-43.1), taking into account all levels of severity. The prevalence of Alexithymia at all levels of severity, meanwhile, was 50.6\% (95\%CI: 43.2-57.9) among the participants interviewed.

The means and deviations of the factors that make up Alexithymia are described in Table 2. When Alexithymia is present, Geriatric Depression is almost three times more likely, OR 2.79 (95\% CI 1.47-5.39), p 0.0014.

Regarding the relationship between these variables and the presence of Geriatric Depression, statistically significant associations were found with the female gender, OR 2.30 (95\%CI 1.08-4.92) $p$ value $0.031\left(\chi^{2}=4.76\right.$; $\left.\mathrm{phi}=0.165, \mathrm{gl}=1, p=0.01\right)$ in favor of women; and one's labor situation $\left(\mathrm{X}^{2}=3.956\right.$, $\left.\mathrm{phi}=-0.15, \mathrm{gl}=1, p=0.01\right)$, in favor of those who did not work, with an OR 1.96 (95\% CI 1.03-3.79), $p 0.025$.

With reference to the comparison of sociodemographic variables and levels of Alexithymia, it was observed that those with a primary educational level and a low occupational level had higher levels of Alexithymia, with a $p$ value $<0.001$ for both cases.

Table 1. Sociodemographic profile of total sample ( $\mathrm{n}=176)$. Buenos Aires, Argentina, 2015.

\begin{tabular}{lc}
\hline Variables & $\mathrm{n}(\%)$ \\
\hline Gender & $48(27.3)$ \\
Male & $12872.7)$ \\
Female & \\
\hline Age range (years) & $128(72.7)$ \\
Younger elderly persons (from 60 to 69) & $48(27.3)$ \\
Older elderly persons (from 70 to 99) & \\
\hline Nationality & $158(89.8)$ \\
Argentinian & $18(10.2)$ \\
Others & \\
\hline Marital Status & $67(38.1)$ \\
Single (Single, Widowed, Separated) & $109(61.9)$ \\
With Partner (Married, Civil Union) & \\
\hline Level of schooling & $102(26.7)$ \\
Primary & $74(73.3)$ \\
Secondary/Tertiary/University & \\
\hline Currently working & $101(57.4)$ \\
No & $75(42.6)$ \\
Yes & \\
\hline Occupational level & $63(35.8)$ \\
Low (craftsman, worker, tradesman) & $113(64.2)$ \\
Medium/High (sales, employee, teacher, professional, executive) &
\end{tabular}


Table 2. Prevalence and levels of Geriatric Depression and Alexithymia ( $\mathrm{n}=176)$. Buenos Aires, Argentina, 2015.

\begin{tabular}{llll}
\hline Variables & $\mathrm{n}(\%)$ & $\mathrm{m}$ & $(\mathrm{de})$ \\
\hline Geriatric depression & $113(64.2)$ & \\
Absent & $47(26.7)$ & & \\
Mild depression & $16(9.1)$ & & \\
Moderate/severe depression & & & \\
Alexithymia & $87(49.4)$ & & \\
Absent & $42(23.9)$ & 13,9 & $( \pm 6,8)$ \\
Indefinite Alexithymia & $47(26.7)$ & $( \pm 5,4)$ \\
Definite Alexithymia & & 10,7 & $( \pm 7,5)$ \\
Factors & & 19,1 & \\
DIF* & & \\
DDF* & & \\
EOT* & & & \\
\hline
\end{tabular}

*DIF: difficulty identifying feelings and distinguishing between feelings and the bodily sensations of emotional arousal; * DDF: difficulty describing feelings to other people; * EOT: a stimulus-bound, externally oriented thinking.

Table 3. Association between sociodemographic variables and geriatric depression $(n=176)$. Buenos Aires, Argentina, 2015.

\begin{tabular}{|c|c|c|c|}
\hline \multirow[t]{2}{*}{ Variables } & \multicolumn{2}{|c|}{ Geriatric Depression } & \multirow[t]{2}{*}{$p^{*}$} \\
\hline & No. n $(\%)$ & Si. $n(\%)$ & \\
\hline \multicolumn{4}{|l|}{ Gender } \\
\hline Male & $37(21.1)$ & $11(6.2)$ & \\
\hline Female & $76(43.2)$ & $52(29.5)$ & 0.031 \\
\hline \multicolumn{4}{|l|}{ Age range (years) } \\
\hline Younger elderly persons (from 60 to 69 ) & $54(30.7)$ & $28(15.9)$ & \\
\hline Older elderly persons (from 70 to 99 ) & $59(33.5)$ & $35(19.9)$ & 0.092 \\
\hline \multicolumn{4}{|l|}{ Nationality } \\
\hline Argentinian & $103(58.5)$ & $56(31.8)$ & \\
\hline Others & $10(5.7)$ & $7(4)$ & 0.964 \\
\hline \multicolumn{4}{|l|}{ Marital Status } \\
\hline Single (Single, Widowed, Separated) & $41(23.3)$ & $26(14.8)$ & \\
\hline With Partner (Married, Civil Union) & $72(40.9)$ & $37(21)$ & 0.521 \\
\hline \multicolumn{4}{|l|}{ Level of schooling } \\
\hline Primary & $27(15.3)$ & $20(11.4)$ & \\
\hline Secondary/Tertiary/University & $86(48.9)$ & $43(24.4)$ & 0.699 \\
\hline \multicolumn{4}{|l|}{ Currently working } \\
\hline No & $59(33.5)$ & $43(24.4)$ & \\
\hline Yes & $54(30.7)$ & $20(11.4)$ & 0.025 \\
\hline \multicolumn{4}{|l|}{ Occupational level } \\
\hline Low (craftsman, worker, tradesman) & $38(21.6)$ & $23(13)$ & \\
\hline Medium/High (sales, employee, teacher, professional, executive) & $78(44.4)$ & $37(21)$ & 0.673 \\
\hline
\end{tabular}


Table 4. Comparison between sociodemographic variables and levels of Alexithymia ( $\mathrm{n}=176)$. Buenos Aires, Argentina, 2015.

\begin{tabular}{|c|c|c|c|}
\hline \multirow{2}{*}{ Variables } & \multicolumn{3}{|c|}{ Alexithymia } \\
\hline & $\mathrm{m}$ & De & $p^{*}$ \\
\hline \multicolumn{4}{|l|}{ Gender } \\
\hline Male & 45.89 & 17.33 & 0.546 \\
\hline Female & 43.15 & 17.39 & \\
\hline \multicolumn{4}{|l|}{ Age range (years) } \\
\hline Younger elderly persons (from 60 to 69 ) & 44.1 & 17.38 & 0.568 \\
\hline Older elderly persons (from 70 to 99) & 43.35 & 17.49 & \\
\hline \multicolumn{4}{|l|}{ Nationality } \\
\hline Argentinian & 43.23 & 17.09 & 0.835 \\
\hline Others & 50 & 19.2 & \\
\hline \multicolumn{4}{|l|}{ Marital Status } \\
\hline Single (Single, Widowed, Separated) & 43.68 & 17.16 & 0.617 \\
\hline With Partner (Married, Civil Union) & 44.03 & 17.57 & \\
\hline \multicolumn{4}{|l|}{ Level of schooling } \\
\hline Primary & 47.23 & 18.98 & 0.001 \\
\hline Secondary/Tertiary/University & 39.11 & 13.47 & \\
\hline \multicolumn{4}{|l|}{ Currently working } \\
\hline No & 45.3 & 19.36 & 0.592 \\
\hline Yes & 41.72 & 13.97 & \\
\hline \multicolumn{4}{|l|}{ Occupational level } \\
\hline Low (craftsman, worker, tradesman) & 40.02 & 19.71 & 0.001 \\
\hline Medium/High (sales, employee, teacher, professional, executive) & 39.11 & 13.47 & \\
\hline
\end{tabular}

* Student's t-test

\section{DISCUSSION}

The present study assesses the prevalence of Geriatric Depression and Alexithymia and their association with the sociodemographic characteristics of elderly persons without known depression.

A prevalence of Depression of $35.8 \%$ was found, considering the total score of the different levels (mild, moderate and severe). This finding coincides with other prevalence studies carried out in recent years, where the increase of these symptoms based on age was identified ${ }^{6,21,22}$. The World Health Organization (WHO) ${ }^{23}$, states that the greatest occurrence of Depression occurs in adults over 65 years old, and highlights the complexity of performing a correct differential diagnosis. This difficulty is due to the presentation of the condition (somatizations), the misattribution of coexisting diseases, as well as polypharmacy, which is common among older adults. Geriatric Depression may be a new episode in an individual who has previously experienced depression, or may represent the late appearance of depression in someone who has never suffered from the condition. Also, some authors consider that the late presentation of Depression is more frequent among the elderly, and is more influenced by environmental factors than by genetic $\operatorname{load}^{7}$. Alexopoulos ${ }^{24}$ points out that in the last years of life different types of losses occur (physical, economic and psychosocial), which, together with the changes associated with the aging process (vascular and degenerative), ${ }^{25}$ may predispose the individual to the emergence of Depression. 
A prevalence of $50.6 \%$ of Alexithymia was found in the present study. The relative newness of the concept, and the fact that analysis has mainly been carried out among the psychosomatic population (chronic asthma, hypertension, chronic urticaria, rheumatoid arthritis, psoriasis, hyperthyroidism, obesity and others) limits comparison with prevalence studies in the general population. In this sense, the results of the present study provide empirical evidence for the study of Alexithymia at a local level, and coincide with the prevalence indicated by Urrutia et al. ${ }^{26}$ in a validation and adaptation of the TAS-20 instrument for Latin America. In this study, a sample of 670 subjects belonging to a general population (non-patients) found a prevalence of Alexithymia of $43.5 \%$ in the subgroup of elderly adults $(n=42$; mean age of $63.4 \%$ years).

Similarly, and considering the type of design of the present study, it is noteworthy that only an association between Alexithymia and Geriatric Depression was identified. In this sense, the results are partially coincident with other studies that link Alexithymia with a greater severity of anxious, depressive symptoms, and a worse response to pharmacological treatment. Other researchers point to Alexithymia as a trigger and/or perpetuator of psychophysiological disorders, and as an index of prognosis in chronic diseases ${ }^{3,7,27}$. Also, studies ${ }^{28}$ have emphasized that the perceptive decline of emotions during old age produces a reduction in spontaneous expression, as well as the accentuation of an anchoring in immediate reality. Therefore, Alexithymia can be considered to be a factor associated with the deterioration of the health of the elderly.

When analyzing Geriatric Depression and sociodemographic variables, significant associations were found with gender and work. Thus, women presented higher levels of Geriatric Depression than men (29.6\% and $6.2 \%$, respectively). These results coincide with those of Lopes et al. ${ }^{22}$, who highlighted a higher frequency of Depression among older adult women. Similarly, Matud et al. ${ }^{29}$, observed that levels of depression remained stable throughout the life cycle of women, until they became senior citizens, when there was a notable increase. Although gender differences have traditionally been analyzed as a consequence of constitutional, genetic and/or endocrine factors, in recent decades the predominance of socio-cultural variables, such as those that condition the way in which men and women manifest and cope with psychological suffering, have been highlighted ${ }^{22}$.

Regarding labor activity, the present study found an association between the absence of work and high levels of Geriatric Depression. These results were in agreement with other studies that described the link between the interruption of work (due to retirement, unemployment, voluntary retirement, or withdrawal from work due to a sick family member, among other reasons) and the presence of depressive symptomatology $y^{30}$. As the activity of work is an axis that organizes daily life, it can become both a source of family conflicts and a buffer against such conflicts. Therefore, the absence of work will modify the social relations of the individual and especially the bond between couples. Thus, this new situation may ease or accentuate binding conflicts, and depending on how the subject deals with these changes, the psychic health of the elderly may be affected ${ }^{13 .}$ In this regard, Vélez Álvarez et al. ${ }^{31}$ found that elderly persons who perform some type of informal work have a good perception of their quality of life and value their health positively. The authors concluded that work gives older adults a sense of meaning in their lives, favoring an active and healthy aging.

Finally, when analyzing Alexithymia and sociodemographic variables significant differences were found, indicating that elderly persons with primary and low occupational levels have high levels of Alexithymia. Similar findings were published by Honkalampi et al..$^{32}$ and Shibata et al..$^{33}$ and, in Argentina, by Urrutia et al. ${ }^{26}$, who found that people with a low educational level had higher Alexithymia scores. Although the study by Urrutia et al. was performed among the general population, as mentioned above, Alexithymia was found to be associated with different psychosomatic diseases. Therefore, educational level and subsequent occupational level could also condition the state of health of a person. In this regard, the $\mathrm{WHO}^{34}$ describes the Social Determinants of Health as those circumstances and contexts that determine the life cycle of a person, from birth to old age. The structural determinants of health are represented by socioeconomic and political context and by the position that individuals occupy in society, according 
to social class, gender, age, ethnicity and territory. They act through intermediary determinants, which are shaped by conditions of employment and work, income and economic situation, lifestyle, psychosocial, behavioral and biological factors, and the health system ${ }^{35}$.

Regarding the limitations of the present study, the selection of the sample was intentional, rather than representative, and therefore the data cannot be generalized to the entire population. Furthermore, with regard to the association between Alexithymia and Geriatric Depression, the future undertaking of a cohort design study is required to verify if this association is causal, and it is important to carry out more evaluation interviews for the purpose of analyzing the factors that make up the Alexithymia scale.

\section{CONCLUSION}

From the results obtained, it is recommended that the evaluation of Geriatric Depression and Alexithymia is included in the clinical care of the elderly, as well as the consideration of the social determinants of health, not only for diagnosis and treatment, but also for the promotion of healthy behavior.

\section{REFERENCES}

1. Instituto Nacional de Estadísticas y Censos. Envejecimiento de la población por provincia o jurisdicción, según censos nacionales 1970 a 2010 [Internet]. Buenos Aires: INDEC; 2011 [acesso em 06 dez. 2013]. Disponível em: http://www.indec.mecon.ar/

2. Rodríguez-Marín J. Psicología Social de la Salud. España: Síntesis; 2014.

3. Morales FF, Abarca AB, Huici Casal C, Fernández Dóls JM. La relación profesional de la salud-enfermo. In: Morales FF. Psicología social aplicada. Bilbao: Desclée de Brouwer; 1985. p. 83-110.

4. Dillon C, Filipin F, Taragano F, Heisecke S, Lopez Camelo J, Allegri R. Geriatric Depression and Cognitive Impairment: a Follow up Study. J Gerontol Geriatr Res. 2016;(5)4:1-8.

5. Martínez de la Iglesia J, Onís Vilches MC, Dueñas Herrero R, Colomer CA, Taberné CA, Luque Luque R. Versión española del cuestonario de Yesavage abreviado (GDS) para el despistaje de depresión en mayores de 65 años: adaptación y validación. Medifam. 2002;(12)10:520-30.

6. Balmon Cruz C, Dorado Primo JA. Detección y prevalencia de trastornos depresivos geriátricos en atención primaria. Rev Asoc.Esp.Neuropsiquiatr [Internet]. 2004 [acesso em 06 dez. 2011]. Disponível em: http://scielo.isciii.es/scielo.php?script=sci_arttext \&pid=S021157352004000200002\&lng=es\&nrm=iso

7. Arancibia MM, Behar AR. Alexitimia y Depresión: evidencia, controversias e implicancias. Rev chil Neuro-psiquiatr. 2015;53(1):24-34.

8. Rojas Ramírez AT, García Méndez M. Funcionamiento familiar como predictor de a alexitimia de acuerdo al índice de masa corporal. Acta Investigación Psicol. 2016;6(2):2469-76.

9. López-Ibor Aliño JJ. Los equivalentes depresivos. Madrid: Paz Montalvo; 1972.

10. Taylor GJ, James CB, Parker JD. A preliminary investigation of alexithymia in men with psychoactive substance dependence. Am J Psychiatr. 1990;147(9):1228-30.

11. Fisch RZ. Alexithymia, masked depression and loss in an holocaust survivor. Br J Psychiatr. 1989;154:708-10.

12. Bamonti P, Heisel M, Topciu R, Franus N, Talbot $\mathrm{N}$, Duberstein P. Association of alexithymia and depression symptom severity in adults 50 years of age and older. Am J Geriatr Psychiatry. 2010;18(1):51-6.

13. Rubio C, Osca A, Recio P, Urien B, Peiró JM. Workfamily conflict, self-efficacy, and emotional exhaustion: a test of longitudinal effects. Rev Psicol Trab Organ. 2015;31(3):147-54.

14. Montesó-Curto P, Aguilar Martín C. Depresión según la edad y el género: análisis en una comunidad. Aten Prim. 2014;46(3):167-72.

15. Schaan B. Widowhood and depression among older europeans: the role of gender, caregiving, marital quality, and regional context. J Gerontol Ser B Psycholl Sci Soc Sci. 2013;68(3):431-42. 
16. Chaves Piani M, Sant'Anna Alves AL, Bervian J, Pancotte J, Doring M, Dalolin BM. Prevalence of depressive symptoms among elderly women from a center of Reference and Care for the Elderly in the city of Passo Fundo, Rio Grande do Sul. Rev Bras Geriatr Gerontol. 2016;19(6):930-8.

17. Montero I, León OG. Sistema de clasificación del método en los informes de investigación en Psicología. Int J Clin Health Psychol. 2005;2(3):115-27.

18. American Psychiatric Association. Diagnostic and statistical manual of mental disorders. 5th ed. Washington, DC: APS; 2013. Seção I, Cautionary statement for forensic use of DSM-5; p. 25.

19. Yesavage JA, Brink TL, Rose TL, Lum O, Huang $\mathrm{V}$, Adey M, et al. Development and validation of a geriatric depression screening scale: A preliminary report. J Psychiatr Res. 1983;17:37-49.

20. Varela S, Barandiarán S, Tonin S, D'Alessio S, Lunazzi HA, Urrutia MI. La escala TAS-20 consensuada para Latinoamérica: un análisis factorial confirmatorio. In: Lunazzi HA. Alexitimia, Cruzando el Puente entre la teoría, la investigación y la clínica. Buenos Aires: Paidós; 2012. Cap. 9; p.197-211.

21. Fukukawa Y, Nakashima C, Tsuboi S, Niino N, Ando F, Kosugi S, Shimokata H. The Impact of Health Problems on Depression and Activities in MiddleAged and Older Adults: Age and Social Interactions as Moderators. J Gerontol Ser B Psychol Sci Soc Sci. 2014;59(1):19-26.

22. Lopes JM, Fernandes SGG, Dantas FG, Medeiros JL. Associação da depressãocom as características sociodemográficas, qualidade do sono e hábitos de vida em idosos do Nordeste brasileiro: estudo seccional de base populacional. Rev Bras Geriatr Gerontol. 2015;18(3):521-31.

23. Organización Mundial de la salud. Depresión [Internet]. Ginebra: OMS; 2017 [acesso em 02 Mar 2017]. Disponível em: http://www.who.int/ mediacentre/factsheets/fs369/es/

24. Alexopoulos GS. Depresión in the elderly. Lancet. 2005;365:1961-70.

25. Hummel H, Weisbrodb C, Boesch L, Himpler K, Hauer K, Hautzinger M, et al. AIDE-Acute Illness and Depression in Elderly Patients. Cognitive Behavioral Group Psychotherapy in Geriatric Patients With Comorbid Depression: a Randomized, Controlled Trial. J Am Med Dir Assoc. 2017;18(4):341-9.
26. Urrutia MI, Tonin S, D’Alessio S, Lunazzi HA. Estudio de muestras recolectadas y resultados obtenidos. In: Lunazzi HA. Alexitimia, Cruzando el Puente entre la teoría, la investigación y la clínica. Buenos Aires: Paidós; 2012. Cap.7, p.151-83.

27. García-Sevilla J, Méndez I, Martínez JP, Cánovas AB, Clemente Y, Boti MA. Alexitimia, deterioro cognitivo y depresión en personas mayores. In: Gázquez JJ, Pérez Fuentes MC, Molero MM, Mercader I, Soler F, Editores. Investigación en Salud y Envejecimiento [Internet]. Vol. 1. Almería: Asoc. Univ. de Educación y Psicología (ASUNIVEP); 2014 [acesso em 16 jun. 2016]. p.185-212. Disponível em: http:// formacionasunivep.com/congresosalud/documents / libro_digital_completo.pdf

28. Medina-Porqueres I, Romero-Galisteo RP, GálvezRuiz P, Moreno-Morales N, Sánchez-Guerrero E, Cuesta-Vargas JS, et al. Alexitimia y depresión en mayores que practican actividad física dirigida. Rev. Iberoam Cienc Act Fís Dep. 2016;5(3):36-48.

29. Matud MP, Guerrero K, Matías RG. Relevancia de las variables sociodemográficas en las diferencias de género en depresión. Int J Clin Health Psychol. 2006;6(1):7-21.

30. Llanes Torres HM, López Sepúlveda Y, Vázquez Aguilar JL, Hernández Pérez R. Factores psicosociales que inciden en la depresión del adulto mayor. Rev Cienc Méd La Habana. 2015;21(1):65-74.

31. Vélez Álvarez C, Escobar Potes MP, Pico Merchán ME. Calidad de vida y trabajo informal en personas mayores en una ciudad intermedia colombiana, 20122013. Rev Bras Geriatr Gerontol. 2016;19(3):415-27.

32. Honkalampi K, Hintikka J, Tanskanen A, Lehtonen J, Viinamaki H. Depression is strongly associated with alexithymia in the general population. J Psychosom Res. 2000;48(1):99-104.

33. Shibata M, Ninomiya T, Jensen MP, Anno K, Yonemoto K, Makino S, et al. Alexithymia is associated with greater risk of chronic pain and negative affect and with lower life satisfaction in a general population: the Hisayama study. PLoS ONE. 2014;9(3):1-8.

34. Organización Mundial de la Salud. Determinantes Sociales de la Salud [Internet]. [Ginebra]: OMS; [2008?] [acesso em 06 set. 2014]. Disponível em: http://www.who.int/social_determinants/es/

35. Acosta LD, Carrizo ED, Peláez E, Roque Torres VE. Condiciones de vida, estado nutricional y estado de salud en adultos mayores, Córdoba, Argentina. Rev Bras Geriatr Gerontol. 2015;18(1):107-18. 